\title{
Population Health Management Telehealth Intervention Medical Research Treating Comorbid Clinical Obesity and Depression in Geriatric Patients Part One: Review of Tele-Medicine Scientific Research
}

\author{
Robelyn A Garcia* \\ Arizona State University, USA \\ *Corresponding author: Robelyn A Garcia, USA \\ Submission: 此 August 08, 2017; Published: 觜 October 27, 2017
}

\section{Introduction}

Population Health Management Tele Health Intervention Medical Research Treating Comorbid Clinical Obesity and Depression in Geriatric Patients. Population health based epidemiologic studies have consistently shown a bidirectional relationship between obesity and depression [1-4]. This Comorbidity is an area of population health management (PHM) in high need of Behavioral Health Consultant - Doctor of Behavioral Health (BHC-DBH) intervention. Behavioral Health Consultants (BHC) has the skills required to address the global obesity epidemic when treating clinically obese geriatric patients with depression. This article is devoted to the goal of providing empirical support for future Telehealth and Tele-Medicine PHM programs in the areas of effectiveness, efficiency and cost effectiveness of the interventions and practice as a feasible treatment for clinical obesity and depression in senior adults Jones [5].

\section{Review of Literature}

The purpose of this review of literature is to synthesize and evaluate the effectiveness of a prescribed and monitored Telehealth physical activity (PA) intervention program for the treatment of clinically obese geriatric patients with depression [1]. It is well documented that multiple obesity-depression co-variations occur across populations [2,6-8]. A 2017 study by Pereira-Miranda, Costa, Queiroz, Pereira-Santos, and Santana, published in the Journal of the American College of Nutrition reports that patients with obesity were $32 \%$ more likely to have depression compared to those who were eutrophic (patients within the normal BMI range). Review of recent research data from another paramount study indicates that obesity is significantly associated with depression among obese healthcare workers Wisetborisut et al. [4].

Obesity is costing America $\$ 605$ billion annually, including over $\$ 300$ billion in direct healthcare costs and over $\$ 300$ billion in indirect medical costs $[9,10]$. One alarming study revealed that more than 78.6 Million (one-third) of adults in the United States are obese Ogden [11]. "No other human condition combines obesity's prevalence and prejudice; sickness and stigma; death and discrimination" Downey [9]. The World Health Organization labels obesity as a public health pandemic and population health epidemic of worldwide proportions Hojjat [12]. Clinical obesity is defined and categorized by a body mass index (BMI) of 30 and above Garcia \& Benavidez [13]. Depression is generally defined as a commonly occurring serious mental state, linked to diminished role functioning, quality of life, medical morbidity, and mortality characterized by a despondent lack of activity and pessimistic sense of inadequacy Kessler \& Bromet [14], Princeton University Word Net [15]. Recent population-based studies support a new definition of the term metabolic depression; this is represented by prolonged depression in direct correlation with obesity $[2,8]$.

\section{Population Identification}

The population is identified as geriatric patients (senior adults aged fifty years and older) diagnosed with comorbid clinical obesity and depression. By the year 2030, 132 million Americans will be older than 50 Housing Studies of Harvard University [16], and it is projected that half of the senior adult population will be obese in that same year Hojjat [12]. Further, the most notable increase in depression and obesity in the United States has been among senior adults Federal Interagency Forum on Aging-Related Statistics [17], Preiss et al. [3]. Population health epidemiologists have found the most significant prevalence rate of comorbid clinical obesity and depression as $66 \%$ reported in obese geriatric patients Preiss et al. [3]. Empirical research has also affirmed that "being obese or overweight is often associated with impaired quality of life and psychological well-being (PWB) in comparison with normalweight people" Giuli et al. [7]. Moreover, there is myriad of evidence listing the geriatric patient population as having the highest rates of obesity Hojjat [12], Smith et al. [18].

Equivalently, depression is widespread and prevalent in geriatric patients. The National Institute of Mental Health calls depression in senior adults a serious population health concern 
National Institute of Mental Health [19]. Surveys suggest from 15 to 50 percent of the geriatric population has experienced depression, while an additional 25 percent of senior adult individuals have long periods of persistent sadness $[8,20,21]$ found that obesity can predict a course of late-life depression. These findings support a lifetime prevalence of comorbid obesity-depression as an emerging global health concern for the senior adult population.

\section{Health Assessments and Screening Tools}

For purposes of this literature review, the presence and severity of obesity is calculated, assessed and diagnosed by using the BMI measurement of [weight (lbs)/height (inches)2] X 703 Corbin [22]. "Studies have shown that BMI levels correlate with body fat and with future health risks. High BMI predicts future morbidity and death. Therefore, BMI is an appropriate measure for screening for obesity and its health risks. Lastly, the widespread and longstanding application of BMI contributes to its utility at the

population level. Its use has resulted in an increased availability of published population data that allows public health professionals to make comparisons across time, regions, and population subgroups" Centers for Disease Control [23]. BMI is the standard measure of obesity based on height and weight Corbin et al. [22], Pereira-Miranda et al. [20]. BMI categories are labeled in Table 1 below.

Table 1: BMI Categories.

\begin{tabular}{|c|c|}
\hline $\begin{array}{c}\text { BMI Senior Adult Population } \\
\text { Scoring and Categories }\end{array}$ & \\
\hline Category & BMI \\
\hline Underweight & $<18.5$ \\
\hline Normal weight & $18.5-24.9$ \\
\hline Overweight & $25-29.9$ \\
\hline Obese & $<30$ \\
\hline Corbin et al. [21], Garcia [28] & \\
\hline
\end{tabular}

For purposes of this literature review, the presence and severity of depression will be assessed by using The Merck Manual of Geriatrics (GDS-15) Geriatric Depression Scale Sheikh \& Yesavage [24]. Both health assessment screening tools have reports of strong validity and reliability Corbin et al. [22], Li et al. [25]. While many clinicians believe that this comorbid geriatric population is too difficult to assess with the Structured Clinical Interview for DSM Disorders (SCID), Marc et al. [26], report that the GDS-15 is easier to administer, offers valid assessment across the geriatric population age range of fifty years and older, education levels, race and gender.

\section{Risk Stratification}

"The next step in the population health process is to stratify patients into meaningful categories for patient-centered intervention targeting, using information collected in the health assessments" Care Continuum Alliance [27]. With obesity and depression, the comorbid occurrence of the behavioral and the medical condition will be addressed, yet obesity would be the medical condition sending the patient to the primary care physician
(PCP) for treatment Jones [5]. The patients are referred to the BHC by their PCP after they have been diagnosed with clinical obesity and depression. The identified population of clinically obese geriatric patients with severe depression (BMI score of $\geq 30$ and GDS-15 score of $\geq 12$ ) fall in the high-risk category on the newly branded Population Health Alliance PHM care continuum Care Continuum Alliance [27]. Many PHM programs target the high-risk population, however obese individuals with mild depression (BMI score $\geq$ 30 and GDS-15 score of 5-11) and no depression (BMI score of $\geq$ 30 and GDS-15 of $\leq 4$ score) also benefit from PHM interventions O’Donnell [28].

\section{Engagement and Intervention}

Health professionals from multiple disciplines concur on the myriad of mental health and physical health benefits that a PA program can provide senior adults Benavidez [29], Corbin et al. [22]. PA has been shown as one of the most effective treatments for obesity and depression in geriatric patients Garcia [30], Xin et al. [21]. Monitoring PA is a key component of weight loss and mental health intervention programs Turner-McGrievy et al. [31]. With ninety-five percent of American adults owning a cell phone, despite level of income and or race, and eighty-eight percent of the United States population having Internet access, a truly prodigious Telehealth opportunity for administering PHM intervention programs presents itself Jones [21], Maheu et al. [32], Pew Research [33].

A Telehealth program for clinically obese geriatric patients is a high risk PHM intervention however, it could also be utilized across the Population Health Alliance care continuum including but not limited to; chronic disease management, prevention, health promotion and or wellness Care Continuum Alliance [27]. Telehealth provides accessibility, affordability, anonymity, acceptability, and adaptability TeleMental Health Institute. Empirical research has affirmed that Telehealth intervention, with a frequency of three to five times per week, can facilitate weight loss and have a beneficial effect on the overall mental health of clinically obese geriatric patients [30-35].

\section{Review of Literature Conclusion}

The analysis of this review of literature is in consonance with current research and recent empirical studies. Clinical obesity, one of the major causes of preventable disease and one of the largest epidemics facing patients today, has more than doubled in the last three decades Chang et al. [2], Preiss et al. [3]. This information is disconcerting and it is vital that healthcare professionals demonstrate healthy behaviors while counseling clinically obese and overweight depressed patients to become physically active though behavioral health, lifestyle medicine, and population health interventions. This can be achieved by emphasizing the benefits of participating in PA program and by providing education on how to overcome perceived and real barriers to healthy activities Garcia [35]. Because there is strong relationship between depression and obesity, PHM intervention programs must address this comorbidity. The intersection of obesity and depression in PHM cannot be 
oppressed or ignored. Synthesis of the research across studies supports the consistent and positive effects of PA on mental health in obese senior adults with depression [36-40]. The reduction in depressive symptoms in clinically obese adults with depression is important in the interest of managing obesity and ultimately eliminating obesity-related morbidity and mortality Xin et al. [21]. Based on this literature review, it is hypothesized that, a monitored PHM Telehealth PA intervention program will have a beneficial effect on clinical obesity and depression among geriatric patients [41-43].

\section{References}

1. Booth HP, Gulliford MC (2017) Obesity management in primary care. The Lancet 389(10079): 1605-1606.

2. Chang JJ, Salas J, Tabet M, Kasper Z, Elder K, et al. (2017) Changes in body mass index and the trajectory of depressive symptoms among rural men and women. J Rural Health 33(2): 190-197.

3. Preiss K, Brennan L, Clarke D (2013) A systematic review of variables associated with the relationship between obesity and depression. Obes Rev 14(11): 906-918.

4. Wisetborisut A, Klibngern H, Jirapornjaroen W, Likhitsathian $\mathrm{S}$, Angkurawaranon C, et al. (2016) Abdominal obesity and depression among obese healthcare workers. Journal of Hypertension 34(9): e303-e304.

5. Jones LM (2017a) IBC 712: Population-Based Health Management. Assignment 1 instructions.

6. Carey M, Small H, Yoong SL, Boyes A, Bisquera A, et al. (2014) Prevalence of comorbid depression and obesity in general practice: a cross-sectional survey. Br J Gen Pract 64(620): 122-127.

7. Giuli C, Papa R, Marcellini F, Boscaro M, Faloia E, et al. (2016) The role of psychological well-being in obese and overweight older adults. Int Psychogeriatr 28(1): 171-172.

8. Marijnissen RM, Vogelzangs N, Mulder ME, van den BRH, Comijs HC, et al. (2017) Metabolic dysregulation and late-life depression: a prospective Study. Psychol Med 47(6): 1041-1052.

9. Downey M (2014) New study pegs obesity costs at $\$ 300$ billion. The Downey Obesity Report.

10. Pianin E, Ehley B (2014) Budget Busting US Obesity Costs Climb Past $\$ 300$ Billion a Year. The Fiscal Times.

11. Ogden C, Carroll M, Kit B, Flegal K (2014) Prevalence of childhood and adult obesity in the United States, 2011-2012. JAMA 311(8): 806-814.

12. Hojjat TA (2013) Economic Analysis of Obesity. Global Conference on Business \& Finance Proceedings 6(1): 81-98.

13. Garcia R, Benavidez D (2016) Tran theoretical Model Key Constructs Applied to the Intervention \& Treatment of Weight Cycling \& Yoyo Dieting Cognitive-Affective Bases of Health for Weight Management International Journal of Complementary and Alternative Medicine 3(3): 00071.

14. Kessler RC, Bromet EJ (2013) The epidemiology of depression across cultures. Annu Rev Public Health 34: 119-138.

15. (2010) Word Net. Princeton University, USA.

16. Joint Center for Housing Studies of Harvard University (2014) Housing America's Older Adults-Meeting the Needs of an Aging Population.

17. Federal Interagency Forum on Aging-Related Statistics (2016) Older Americans 2016: Key Indicators of Well-Being. Federal Interagency Forum on Aging-Related Statistics. U.S. Government Printing Office, Washington, DC, USA.
18. Smith AW, Borowski LA, Liu B, Galauska DA, Signore C, et al. (2011) U.S. Primary Care Physicians' Diet, Physical Activity, \& Weight-Related Care of Adult Patients. Am J Prev Med 41(1): 33-42.

19. (2016) Older adults and depression. National Institute of Mental Health, USA.

20. Miranda PE, Costa PRF, Queiroz VAO, Santos PM, Santana MLP (2017) Overweight and obesity associated with higher depression prevalence in adults: A systematic review and meta-analysis. Journal of the American College of Nutrition 36(3): 223-233.

21. Xin L, Vitetta L, Kostner K, Crompton D, Williams G, et al. (2015) The Effects of Tai Chi in Centrally Obese Adults with Depression Symptoms. Evidence-Based Complementary and Alternative Medicine 879712: 1-8.

22. Corbin C, Welk G, Corbin W, Welk K (2012) Concepts of physical fitness. $\left(17^{\text {th }}\right.$ edn), McGraw-Hill Higher Education, USA.

23. (2017) Body Mass Index: Considerations for Practitioners. Centers for Disease Control and Prevention (CDC), Taiwan.

24. Sheikh JI, Yesavage JA (1986) Clinical gerontology: A guide to assessment and intervention. In: Brink TL (Ed.) The Haworth Press, New York, USA, pp. $165-173$.

25. Li Z, Jeon Y, Low L, Chenoweth L, O'Connor DW, et al. (2015) Validity of the geriatric depression scale and the collateral source version of the geriatric depression scale in nursing homes. Int Psychogeriatr 27(9): 1495-1504.

26. Marc LG, Raue PJ, Bruce ML (2008) Screening performance of the 15item geriatric depression scale in a diverse elderly home care population. Am J Geriatr Psychiatry 16(11): 914-921.

27. Care Continuum Alliance (2012) Implementation and Evaluation: A Population Health Guide for Primary Care Models.

28. O’Donnell R (2017) Informative Conversation about Population Health Management. Population Health Management, USA.

29. Benavidez D (2017) Improving mood in geriatric individuals. (Doctoral Dissertation). United States Sports Academy, Daphne, Alabama, USA.

30. Garcia RA (2011) Does online "Working Out Work" as a treatment and prevention for depression in older adults? An analysis of a prescribed and monitored exercise program administered via the Internet for senior adults. Arizona State University, Tempe, USA.

31.Jones LM (2017b) IBC 712: Population-Based Health Management. Assignment 1 instructions.

32. Marlene MM (2017) Career Paths in Telemental Health- In: Maheu MM, Drude KP, Wright SD (Eds.), Career Paths in Telemental Health, Springer International Publishing, Switzerland.

33. Pew Research Project (2017) Mobile Technology Fact Sheet. Pew Research Center, Washington, DC, USA

34. Thomas J, Bond D (2014) Review of Innovations in Digital Health Technology to Promote Weight Control. Curr Diab Rep 14(5): p. 485.

35. Garcia R (2015) Integrative Mind-Body Medicine as a Treatment for Psychophysiologic Disorders Utilizing the Seven Keys to Treating Stress Illness. International Journal of Complementary and Alternative Medicine 1(3): p. 00017.

36. Franx G, Oud M, de Lange J, Wensing M, Grol R, et al. (2012) Implementing a stepped-care approach in primary care: results of a qualitative study. Implement Sci 7: 8 .

37. Friedman B, Heisel MJ, Delavan RL (2005) Psychometric properties of the 15 -item geriatric depression scale in functionally impaired, cognitively intact, community-dwelling elderly primary care patients. J Am Geriatr Soc 53(9): 1570-1576.

38. (2017) Why Use BMI? Obesity Prevention Source. Harvard School of Public Health, USA.

How to cite this article: Robelyn A Garcia. Population Health Management Telehealth Intervention Medical Research Treating Comorbid Clinical Obesity and Depression in Geriatric Patients Part One: Review of Tele-Medicine Scientific Research. Res Med Eng Sci. 1(5). RMES.000525. 2017. 
39. Leatherdale ST, Laxer RE (2013) Reliability and validity of the weight status and dietary intake measures in the COMPASS questionnaire: are the self-reported measures of body mass index (BMI) and Canada's food guide servings robust? Int J Behav Nutr Phys Act 10: 42.

40. Paltzer J, Brown RL, Burns M, Moberg DP, Mullahy J, et al. (2017) Substance Use Screening, Brief Intervention, and Referral to Treatment Among Medicaid Patients in Wisconsin: Impacts on Healthcare Utilization and Costs. J Behav Health Serv Res 44(1): 102-112.

41.(2016) Senior Services Sponsorship Opportunities. Scottsdale Senior Services, USA.
42.Spring B, Duncan J, Janke E, Kozak T, McFadden H, et al. (2013) Integrating technology into standard weight loss treatment: A randomized controlled trial. JAMA Intern Med 173(2): 105-111.

43.Zhang O, Liao J, Liao X, Wu Min X, Changzheng W, et al. (2014) Disease knowledge level is a noteworthy risk factor of anxiety and depression in patients with chronic obstructive pulmonary disease: A cross-sectional study. BMC Pulmonary Medicine 14: 92. 